\title{
Virtual Issue \#2: Contribution of Chinese research to the field of environmental contamination and toxicology: The most cited papers published in BECT from 2012-2017
}

\author{
Huan Zhong ${ }^{1,2} \cdot$ Cheng Gu$^{1}$
}

Received: 7 February 2018 / Accepted: 28 February 2018 / Published online: 30 March 2018

(c) Springer Science+Business Media, LLC, part of Springer Nature 2018

China was recently recognized as one of the global leaders in contributions to science and engineering, as indicated by the numbers of published articles and other indices (Showstack 2018). Over the last decade, China has provided increasing support for research on environmental issues. This has allowed Chinese scholars to contribute significantly to the fields of environmental science and engineering. For over 50 years, the Bulletin of Environmental Contamination and Toxicology (BECT) has been the venue for the rapid publication of research covering air, soil, water, and food contamination. The journal is the preferred platform for Chinese researchers to report advances and discoveries in these and related fields. According to http://www.muchong.com/bbs (2018), one of the most well-known academic online discussion forums in China, BECT is favored by Chinese students and scholars mainly because (1) it offers a relatively rapid process of peer-review and publication, and (2) it publishes papers in a concise format. According to the Web of Science, 24\% of all papers published in the BECT from 2007 to 2017 were from Chinese scholars.

A closer examination of these papers offers an insight into the recent research interests of the Chinese academic community. Among the most frequent topics were environmental contamination, toxicology, environmental processes, and method development. Specifically, $37 \%$ of the publications were related to 'environmental contamination,' including reports on levels of contaminants in different environmental media and an assessment of associated risks; $24 \%$ focused on 'toxicology,' $23 \%$ on 'method development,' and $16 \%$ on the

Cheng Gu

chenggu@nju.edu.cn

1 Nanjing University, School of Environment, State Key Laboratory of Pollution Control and Resource Reuse, Nanjing, Jiangsu, People's Republic of China

2 Environmental and Life Sciences Program (EnLS), Trent University, Peterborough, ON, Canada 'environmental processes of contaminants' (e.g., the transfer, partitioning, degradation, and speciation of contaminants in the environment). A second group of topics comprised those examining specific contaminants, including organic contaminants (60\% of the published papers in this group), heavy metals $(28 \%)$, and others (13\%, e.g., nutrient pollution). The focus on organic pollution reflects the concerns in China regarding these compounds. The focus of a third group was environmental media, i.e., water, soil/sediment, air, and food. Over half $(51 \%)$ of the publications examined contamination in soils and sediments. This predominance is not surprising considering the increasing efforts by the Chinese government to remediate contaminated soils and sediments, especially after the recent national-scale survey by China's Ministry of Environmental Protection (MEP) and Ministry of Land and Resources (MLR) (MEP \& MLR 2014). Within this third group, approximately $39 \%$ of papers investigated water pollution, which has been the focus of environmental protection measures in China in the last few decades. Unfortunately, despite the priorities of the Chinese government regarding air pollution, little attention has been paid to the topic (5\%). More submissions and publications from Chinese scholars on air pollution are expected in the next 5 years.

In this Virtual Issue of BECT, we have included 22 of the most frequently cited papers, selected from papers by Chinese scholars, that were published in the BECT during the period 2012-2017 (http://www.springer.com/environment/ pollution+and+remediation/journal/128). These excellent papers, together with the statistical data presented above, exemplify the recent research pursuits of Chinese scholars. By presenting these papers in the 100th anniversary volume of the BECT, we highlight the contributions of Chinese researchers to the fields of environmental contamination and toxicology. 


\section{References}

Ministry of Environmental Protection (MEP) and Ministry of Land and Resources (MLR), The People's Republic of China (2014) http:// www.mep.gov.cn/gkml/hbb/qt/201404/t20140417_270670.htm. Assessed 1 February 2018

Showstack R (2018) China catching up to United States in research and development. Earth \& Space Science News (Eos), 99, https:// doi.org/10.1029/2018EO091489. Published on 24 January 2018. http://www.muchong.com/bbs. http://muchong.com/bbs/journ al.php?view $=$ detail $\&$ jid $=1408$. Assessed 1 February 2018 